\title{
DE GERENTE SÊNIOR A DIRETOR EXECUTIVO: QUANTOS PASSOS DEVO DAR? \\ O CASO KROTON, ANHANGUERA E ESTÁCIO
}

\author{
FROM SENIOR MANAGER TO CEO: HOW MANY STEPS SHOULD I TAKE? \\ THE KROTON, ANHANGUERA AND ESTÁCIO CASE
}

\author{
JEFFERSON PEREIRA DE ANDRADE \\ Universidade Federal da Paraíba \\ Mestre em Ciências Contábeis pelo PPGCC/UFPB \\ Orcid: http://orcid.org/0000-0001-8967-8827 \\ E-mail pereira_jp2008@hotmail.com
}

Universidade Federal da Paraíba, Campus I - Lot. Cidade Universitária, PB, CEP: 58051-900

\author{
DAVI JÔNATAS CUNHA ARAÚJO \\ Universidade Federal da Paraíba \\ Doutorando em Ciências Contábeis pelo PPGCC/UFPB \\ Orcid: http://orcid.org/0000-0002-7819-5691 \\ E-mail:davijonatasss@gmail.com \\ WENNER GLAUCIO LOPES LUCENA \\ Universidade Federal da Paraíba \\ Doutor em Ciências Contábeis e Professor do PPGCC/UFPB \\ Orcid: https://orcid.org/0000-0002-2476-7383 \\ E-mail:wdlucena@yahoo.com.br
}

\begin{abstract}
RESUMO
Esse caso busca auxiliar a compreensão de estudantes de graduação ou pós-graduação em como o profissional atua em situações que envolvem rearranjos organizacionais, mais especificamente, um processo de incorporação entre empresas. O processo de incorporação analisado neste caso foi o celebrado entre a Kroton Educacional S.A. e a Anhanguera Participações S.A., no ano de 2013, assim como a incorporação proposta entre a Kroton e a Estácio Participações S.A, que em 2017, não chegou a ser celebrada, por determinação do $C A D E$, que decidiu não aprovar o projeto de aliança estratégica entre aquelas organizações. Baseado nesses dois acontecimentos, o caso foi elaborado com o intuito de que os estudantes pudessem compreender como as incorporações acontecem na prática, de maneira que possam enxergar a aplicação da teoria na prática. Os personagens e diálogos foram construídos com base nos eventos descritos em ordem cronológica; e na relação entre a Teoria Institucional e o conteúdo apresentado nos comunicados ao mercado, fatos relevantes e as notícias publicadas na época. Esse caso para ensino busca fornecer uma visão analítica da atuação de um profissional no processo de incorporação, por meio de lentes institucionais.
\end{abstract}

Palavras-chave: Incorporação. Atuação Profissional. Teoria Institucional.

Data de submissão: 19/10/2018. Data de aceite: 30/11/2019. Data de publicação: 20/12/2019. 


\begin{abstract}
This case seeks to help the understanding of graduate or undergraduate students in how the professional acts in situations that involve organizational rearrangements but specifically a process of incorporation between companies. The process of incorporation analyzed in this case was the signed by Kroton (S.A.) and Anhanguera Participações S.A., in the year of 2013, as well as the proposed incorporation between Kroton and Estácio Participações S/A, which in 2017 was not signed by order of CADE, which decided do not approve the alliance project between those organizations. Based on these two events, the case was designed with the intention that students could understand how the incorporations happen in practice so that they can see the application of theory on the practice. The characters and dialogues were built based on the events described in chronological order; and in the relationship between Institutional Theory and the content presented in market announcements, relevant facts and published news in season. This teaching case seeks to provide an analytical view of the acting of a professional in the incorporation process through of institutional lenses.
\end{abstract}

Keywords: Incorporation. Professional acting. Institutional Theory.

\title{
1 INTRODUÇÃO
}

Paulo era gerente sênior da Kroton Educacional S.A. há vinte anos. Apesar de estar muito feliz com seu cargo, ele nunca escondeu sua vontade de desempenhar funções com maior autoridade e de ocupar cargos com posição mais alta na estrutura hierárquica da instituição. Em contrapartida, a governança da Kroton parecia nunca enxergar a disposição de Paulo em crescer dentro da empresa, mesmo ele apresentando um bom desempenho constantemente, tanto no que se refere ao alcance de suas metas individuais, como nas alcançadas pela equipe gerenciada por ele.

Era manhã de sol do dia 05 de janeiro de 2013, Paulo saia para mais um dia de trabalho até que, antes de entrar em seu carro... o inesperado acontece!

-Alô?! Do outro lado da linha indagava a senhora Solange Bravo, que há cinco anos, ocupava a chefia do Conselho de Operações Fiscais da Kroton.

-Paulo?!

Paulo estava atordoado, pois receber ligações de pessoas que ocupavam cargos daquela magnitude na empresa nunca seria tratado como um evento comum para ele...

-Sim! Fala com ele mesmo! Respondeu Paulo.

-Hoje você terá um dia bem diferente! Apontou Solange, com um certo "ar de ironia" na voz, o que também não pareceu "algo normal" para Paulo, que seguiu ouvindo atentamente o que seria dito logo após aquela "leve introdução" na conversa.

- Ao chegar na empresa, preciso que você se dirija imediatamente à Sala de Reuniões. Nós precisamos conversar. Ela continuou: - De antemão, já lhe adianto que você não deve se preocupar com as tarefas do seu setor, pois já designamos um responsável para desempenhálas, inclusive as atividades de sua equipe também, que já foi avisada sobre a situação que lhe envolve. Conversamos melhor daqui há... trinta minutos?!

Paulo estava atônito. Em sua cabeça não havia espaço para pensar em outra coisa a não ser: "O que fiz de errado?" Mesmo confuso e angustiado, reuniu forças para respirar fundo e responder a "imposição afirmativa" de Solange Bravo:

-Claro, Senhora Solange! Isso! Em até trinta minutos! Muito obrigado! 
Paulo não sabia de onde retirou forças para agradecer ao final. Estava aflito...

-O que eu fiz de errado? O que aconteceu? No caminho para empresa, Paulo se perguntava. Naquele dia, parecia que a Avenida Mineira era mais longa do que nos demais. Antes conhecida por Paulo como seu "caminho da roça", naquele momento, a Avenida Mineira parecia completamente desconhecida para ele.

Ao chegar na Kroton, Paulo teve dúvidas quanto ao lugar em que deveria estacionar seu carro. Não havia tempo para pensar a respeito disso, visto que havia um grupo de executivos a sua espera na Sala de Reuniões e que ele não sabia do que se tratava... seria seu último dia ali? Seria alguma proposta? Porque se fez algo errado, a ponto de o substituírem e até já anunciarem a sua equipe sobre "determinada situação que o envolvia", insistiram em conversar com ele?

Sufocado com tantas suspeitas, Paulo respirou fundo, pressionou a maçaneta da porta e adentrou à Sala de Reuniões.

\subsection{NA SALA DE REUNIÕES}

Solange Bravo conversava em voz baixa:

- Mas, será essa é uma boa ideia? Não deveríamos avaliar melhor o desempenho da organização antes de tomarmos essa iniciativa? Lembro-me bem de quando elencamos as metas no planejamento, as estabelecemos com base na previsão de que os indicadores financeiros continuariam apresentando aqueles mesmos níveis de liquidez, com um endividamento controlado, por no mínimo três anos. Mas... você sabe! Nós não temos como garantir isso! Previsões são previsões!

Alberto Bravo tenta acalmar sua esposa, buscando palavras no mesmo tom usado por ela ao Ihe fazer o último alerta.

-Calma, querida! O Paulo é um bom rapaz, eu confio em seu trabalho. Já faz dez anos que ele trabalha aqui e nunca nos causou problemas. Eu tenho sempre observado sua motivação e disciplina durante esses anos.

-Alberto, apesar de todo respeito que eu tenho a você e a sua capacidade de perceber "talentos", retruca Solange, - Eu gostaria que você ao menos entendesse que não se trata de "causar problemas", se trata de colocar alguém a frente de um projeto de curtíssimo e médio prazo, com um alto...

A conversa foi interrompida pela entrada súbita de Paulo na Sala de Reuniões.

- Grande Paulo! Lhe saúda o Senhor Alberto Bravo!

-Olá, Sr. Alberto! Como o senhor está? Pergunta Paulo, que com a mão direita gelada e trêmula, reúne forças para estendê-la em direção ao Sr. Alberto.

- Olá, Paulo! Espero que estejas bem. Saúda-Ihe a Sra. Solange.

-Sim, estou Sra.! Responde Paulo, que sem perceber, decide "dar início a reunião", indagando sobre qual o motivo de sua convocação e porque tudo estava acontecendo daquela maneira.

- Paulo, não precisa ficar nervoso! Há dez anos trabalhando aqui e você ainda não nos conhece? Indaga Alberto.

- Paulo, nós temos uma proposta a lhe fazer. Interrompe Solange, que continua sua colocação: - Precisamos de você agora, não mais como gerente da qualidade de nossos processos educacionais, mas como diretor executivo de operações acadêmicas, logísticas e de qualidade. 
- Para isso, nós precisamos que você tenha conhecimento de algumas informações. Ressalta Alberto, que continuou a instruí-lo, sob o olhar atento de sua esposa:

- Nós preparamos uma apostila com informações institucionais, que esclarecerão algumas das funções que você desempenhará em seu novo cargo. Concederemos um período de afastamento das atividades da empresa por sete dias, a contar da data de hoje 05/01/2013, para que depois dessa capacitação, você retorne totalmente "inteirado" sobre como deverá desempenhar as funções de seu novo cargo.

\subsection{AO CHEGAR EM CASA}

Paulo está radiante. Ele nunca imaginou receber uma função tão importante na organização, mesmo sem saber do que se tratava especificamente. Além de radiante, ele está ansioso e não vê a hora de dar início a leitura de sua apostila.

Ao dar início a sua tão sonhada leitura, já no primeiro capítulo do material, Paulo se depara com as seguintes informações:

"A reorganização societária busca obter vantagem econômica e fiscal, por meio das operações de fusão, cisão e incorporação de empresas (WEBER, 2008). Essas operações são distintas entre si e possuem diferentes implicações. Conforme a Lei das Sociedades Anônimas (Lei № 6.404/76), no processo de incorporação, uma ou mais sociedades são absorvidas por outra, que lhes sucede em todos os direitos e obrigações. No processo de fusão, duas ou mais sociedades se unem, para que uma nova sociedade seja formada, que também Ihes sucederá em todos os direitos e obrigações. No processo da cisão, a companhia transfere parcelas do seu patrimônio para uma ou mais sociedades, extinguindo-se a companhia cindida, se houver versão de todo o seu patrimônio ou dividindo o seu capital, se parcial.

A Kroton S.A. vem analisando o processo de incorporação como um instrumento estratégico e como um recurso para expandir sua atuação de mercado entre os anos de 2013 a 2016. É sabido que existem muitos fatores envolvidos em um processo de incorporação: o fator mercado, que nos leva a ser mais competitivos; o fator sociedade, que nos leva a beneficiar um determinado grupo social; e o fator governo, que nos dá a possibilidade de pagar menos tributos. Em suma, com esse projeto, buscamos expandir nossa atuação no mercado, por meio da diversificação de nossas atividades."

Apesar de não ter entendido do que se tratavam aquelas informações ao certo, Paulo permanecia cheio de expectativas para o que ele iria encontrar nas próximas seções da apostila. Após o término do primeiro capítulo, ele se depara com uma breve seção intitulada "Justificativa da viabilidade do projeto", que trazia as seguintes informações:

"O que justifica a escolha de efetuarmos a incorporação se dá mediante ao fato de que, as empresas que participam desse processo alcançam rápida expansão ao adentrarem em novos mercados. Além disso, obtém racionalização produtiva com economia de escala e ganham ativos complementares para poder desempenhar mais atividades.

Consideramos que as organizações interagem e moldam o ambiente externo a elas, por isso, estamos atentos ao fato de que a estratégia e a estrutura de nossas atividades, podem interferir no processo de incorporação entre organizações, tanto quanto podem influenciar o desempenho operacional e financeiro de qualquer organização. No caso da Kroton Educacional, agregamos a incorporação como parte de sua estratégia de crescimento e liderança de mercado." 


\subsection{O HISTÓRICO DA KROTON EDUCACIONAL S.A.}

Paulo permanecia cheio de expectativas. Apesar de não possuir muita experiência na área, àquela altura do campeonato, ele já havia percebido que havia sido chamado pelos Srs. Bravo, a conduzir uma missão na Kroton Educacional, algo muito além de somente ocupar um cargo mais alto na hierarquia da empresa.

Coincidente ao sentimento de orgulho por fazer parte daquela instituição, Paulo vira a página referente a justificativa da viabilidade do projeto e passa a ler as informações que davam identidade a instituição a qual ele "doou" dez anos de sua vida. Como ele mesmo intitulava: "os dez anos mais importantes de sua vida, os dez anos de maior aprendizado".

Logo abaixo da logomarca, à direita do papel que dividia o histórico da Kroton Educacional S.A. das demais seções lidas até o momento, Paulo passa a ler em voz alta os seguintes trechos:

"A Kroton Educacional S.A é uma empresa mineira, atuante no mercado de educação básica, superior e a distância, e que hoje conta com 1.071 .000 alunos de graduação e pósgraduação, 677 pólos de educação a distância (EAD), 127 campis em todo o país, 53 mil alunos em cursos não regulados e 290 mil alunos de educação básica, o que a torna uma das principais organizações do setor de educação do país.

Regida sobre a visão de se tornar líder de mercado, a empresa foi criada em 1966 em Belo Horizonte e ao longo de seus mais de 50 anos de existência, tem buscado a liderança por meio da ampliação do seu mercado de atuação e através da aquisição e incorporação de outros empreendimentos do setor. Como? Nos anos de 2011 e 2012, a empresa fez a aquisição de sete instituições: IUNI Educacional, Faculdade Atenas Maranhense, Faculdade União, Faculdade do Sorriso - FAIS, Universidade Norte do Pará - UNOPAR, Centro Universitário Cândido Randon e o Centro Universitário Leonardo da Vince - Uniasselvi."

Paulo não conseguia controlar a emoção. Essa seção o fez lembrar de muitos momentos vividos na organização. Ele lembrava bem das inúmeras viagens realizadas às regiões Norte e Nordeste do Brasil para capacitar novos gerentes, professores e colaboradores.

Ele lembrou ainda dos dois meses consecutivos que ficou impossibilitado de visitar sua família, devido a requisição de uma consultoria para UNOPAR, em que ao final da avaliação de quais recomendações foram atendidas por aquela instituição - pós consultoria, ele descobriu que mais de $80 \%$ das recomendações efetuadas por ele, não haviam sido atendidas, o que o obrigou a prestar uma nova consultoria, só que daquela vez, com a deliberação de mecanismos mais autocráticos e impositivos.

Paulo riu ao lembrar que esta foi uma das poucas vezes que ele precisou ser impositivo na Kroton.

\subsection{PERTO DA PROPOSTA: ALGUMAS REFLEXÕES.}

Paulo não era um grande conhecedor de como acontecia um processo de incorporação de fato, apesar de sua formação acadêmica e dos dez anos na Kroton trabalhando com inúmeras consultorias, treinamentos e capacitação, ele nunca havia participado de um 
processo como esse na prática. E agora, ele já havia percebido que os Srs. Bravo o haviam convocado para estar à frente da execução desse projeto.

"-Não se tratava apenas de ocupar um cargo de direção executiva, mas conduzir um processo de incorporação de outra instituição". Pensou Paulo. Ele era consciente de que esse processo traria muitas mudanças para o ambiente organizacional da instituição onde trabalhava, inclusive que, em decorrência dessas mudanças, o seu cargo de direção executiva de operações acadêmicas, logísticas e de qualidade poderia ser desmembrado em três, devido o volume maior de atividades, decorrente da incorporação.

Não somente isso, Paulo era consciente que, decorrente da incorporação, toda a identidade institucional da Kroton quanto a missão, visão, valores e objetivos poderiam ser reformuladas, de maneira que isso "respingaria" na estratégia, no planejamento e nas metas de toda a organização em si.

“Prioridades podem mudar!". Pensou Paulo. Ele lembrou de um episódio que ocorreu, decorrente da expansão das atividades na modalidade EAD da Kroton. Com o aumento das matrículas decorrentes do fornecimento de cursos naquela modalidade, seu cargo de gerência foi desmembrado, de maneira que ele passou a gerenciar somente as ações que diziam respeito a qualidade das operações acadêmicas, justificado pelo mesmo motivo: aumento do volume de atividades. Isso o levou a lembrar da redução salarial que sofreu na época e que o obrigou a reformular todo seu orçamento doméstico, alterando todas as suas prioridades.

Por um momento, Paulo se sentiu inseguro, mas como de costume, rapidamente sua insegurança deu lugar a motivação de vencer aquele desafio. Nesse momento, ele lembrou dos Srs. Bravo e das motivações que poderiam tê-los levado a escolher ele para executar esse projeto; e decidiu seguir em frente.

Paulo balança a cabeça e retoma a leitura da apostila, que agora conta com uma seção que introduz detalhes técnicos de como um processo de incorporação ocorre. Paulo espera entender depois da leitura dessa seção, em especial, como o processo de incorporação acontece na prática. Os trechos da seção apresentavam as seguintes informações:

"Um processo de incorporação é sujeito a três condições básicas: a primeira, relacionada a estrutura societária das empresas. Por se tratar de empresas de capital aberto, é necessário que as organizações obtenham autorização nas suas assembleias gerais, para que seja dado início ao processo. A segunda condição determina que as empresas mantenham auditorias contábeis e financeiras de seus processos organizacionais regularmente. A terceira e principal condição, decorrente da política de defesa econômica do país. Baseada na Lei $12.529 / 11$, as empresas devem submeter sua proposta de incorporação ao Conselho Administrativo de Defesa Econômica (CADE) que irá avaliar os potenciais resultados da operação na livre concorrência no país. De acordo com essa lei, a dominação acentuada de uma única empresa ou de um grupo econômico no mercado corresponde a uma infração econômica, exceto quando essa dominação corresponda ao resultado natural de uma gestão eficiente."

Decorrente da leitura dessa seção, Paulo lembrou de um trabalho desenvolvido por ele, enquanto acadêmico, na disciplina fundamentos conceituais, em que ele deveria dissertar sobre a importância do CADE para assegurar a livre concorrência no mercado. Ele chegou a 
rir, ao lembrar que no momento da correção de seu texto, o professor chamou sua atenção por ele não ter usado fontes confiáveis para embasar suas ideias.

Paulo estava decidido...chegou a hora de voltar para Kroton e apresentar suas ideias aos Srs. Bravo, os quais ele tinha certeza de que estavam aguardando ansiosos para o que ele iria Ihes apresentar. Isso acontecia sempre que havia algo novo a ser implantado na empresa, Paulo já estava acostumado...

\section{DE VOLTA PARA KROTON: A PRIMEIRA INCORPORAÇÃO.}

Na manhã nublada do dia 22 de abril de 2013, a Kroton juntamente com a Anhanguera Educacional Participações S.A (Anhanguera) emitiram um comunicado ao mercado, informando a celebração de um acordo de associação entre as duas empresas.

Paulo estava cheio de expectativas, mas não tanto quanto os Srs. Bravo que, na noite anterior, deram uma festa em sua residência situada em um condomínio fechado perto da Avenida Mineira, por ocasião da celebração do acordo de associação entre as organizações. A expectativa dos Srs. Bravo se justificava pelo fato de que o projeto de incorporação de curtíssimo prazo, elaborado em tão pouco tempo, mas especificamente, no segundo semestre de 2012, estivesse dando certo.

A Kroton iria incorporar as ações de emissão da Anhanguera, e com isso, seria possível combinar os ativos, os talentos e as competências das duas empresas, eles acreditavam que essa sinergia seria capaz de agregar qualidade aos serviços prestados a sociedade. Os Srs. Bravo também acreditavam que, com a celebração do acordo, as empresas poderiam expandir suas atividades de forma complementar, uma vez que, a Kroton teria como foco o ensino na modalidade EAD e a Anhanguera, a educação presencial.

Geograficamente, a Kroton tinha atividade presencial mais acentuada nos estados de Minas Gerais, Mato Grosso, Bahia, Santa Catarina e Paraná, enquanto a Anhanguera tinha sua atividade concentrada nos estados de São Paulo, Mato Grosso do Sul, Goiás, Santa Catarina e Rio Grande do Sul.

- Será a combinação perfeita! Apontou o Sr. Alberto, quando, na reunião matinal daquele dia, Paulo apresentava a imagem que ilustrava a atuação de ambas as instituições por estados no Brasil. A imagem é apresentada na Figura 1.

Figura 1 - Estados onde a Kroton e a Anhanguera concentravam suas atividades.

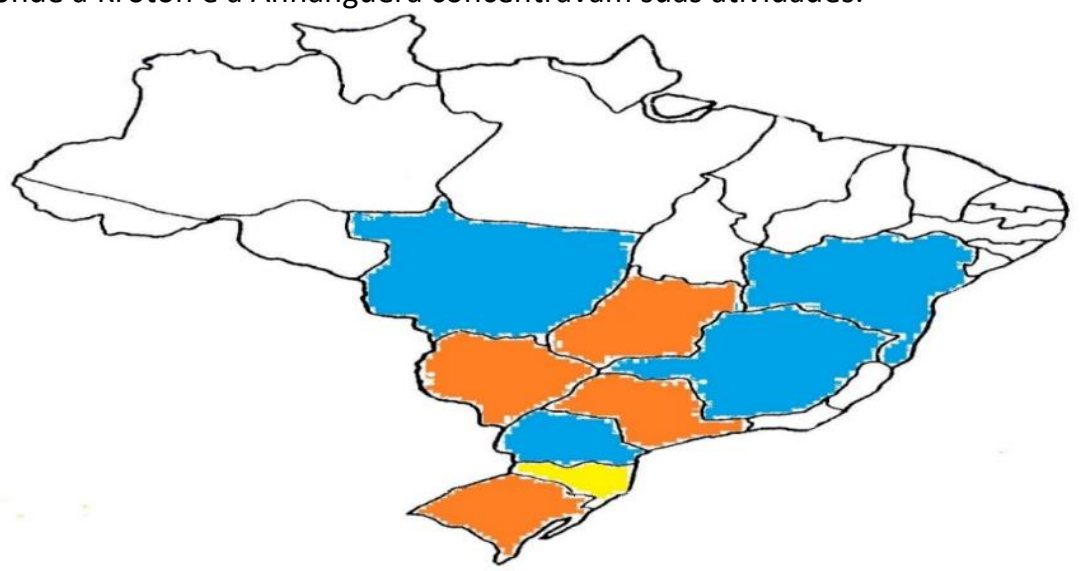

Nota. Os estados destacados em azul, correspondem aos estados em que as atividades da Kroton se concentravam, nos destacados em laranja, onde as atividades da Anhanguera estavam concentradas; nos destacados em amarelo, havia a concentração proporcional das atividades das duas organizações.

Fonte: Elaborado pelos autores (2017). 
Os Srs. Bravo esperavam que com o sucesso da operação, a nova organização oriunda da incorporação, mantivesse seu capital disperso, sem que existisse um acionista controlador. Eles acreditavam que com a dispersão do capital, os investidores dariam mais credibilidade a instituição no mercado. De maneira que, inicialmente, ficou definido que a companhia resultante da incorporação teria $57,48 \%$ do capital em posse dos acionistas da Kroton e 42,52\%, em posse dos acionistas da Anhanguera.

No dia 16 de junho de 2013, Paulo estava radiante. Todas as metas definidas para o processo de incorporação haviam sido alcançadas. De maneira que neste mesmo período, tanto a Kroton como a Anhanguera, conseguiram anunciar a conclusão da primeira etapa do processo, com o fim dos trabalhos das auditorias e o encaminhamento do texto do processo para apreciação e parecer do CADE.

Os Srs. Bravo acreditavam que o sucesso dessa primeira etapa se deu pela maneira clara com que Paulo conseguiu transmitir as informações do projeto de incorporação na Assembleia Geral ocorrida três meses antes ao envio do processo para análise e parecer do CADE.

Apesar da competência de Paulo em conduzir esse processo sozinho, em agosto de 2013, os Srs. Bravo decidiram contratar a Mckinsey \& Company, uma empresa prestadora de serviços de consultoria, para auxiliar na execução da etapa final do processo de incorporação. Por confiar sobremaneira no trabalho de Paulo, os Srs. Bravo solicitaram que ele fosse o responsável por supervisionar todo o processo da consultoria, com a incumbência de fornecer todas as informações solicitadas pela equipe, pelo menos as que fosse possível ser entregues. Ninguém melhor do que Paulo para selecioná-las...

Com a auxílio da equipe da Mckinsey \& Company, os Srs. Bravo conseguiram estimar os potenciais resultados da sinergia entre a Kroton e a Anhanguera com a futura incorporação. As análises preliminares indicavam que a sinergia geraria um valor em torno de $R \$ 300$ milhões, resultantes de uma redução de custos estimados em $60 \%$, um aumento de receitas de $30 \%$ e uma melhora na "saúde financeira" das empresas combinadas de $10 \%$. A previsão da Mckinsey \& Company apontava que esses resultados se tornariam visíveis em até 36 meses a partir da data da incorporação.

Apesar de tudo está caminhando bem, os Srs. Bravo não conseguiam esconder sua preocupação acerca da atuação do CADE em prol da incorporação. Na visão deles, as ações desempenhadas pelo órgão serviam mais para prejudicar do que beneficiar esse tipo de processo. Os Srs. Bravo lembravam bem da tentativa de fusão da Kroton com outra instituição há alguns anos, que eles julgaram não ter sido bem-sucedida por certa "má vontade" do CADE.

No CADE, foi previsto que o processo transitasse entre sua Superintendência Geral e seu Tribunal. Em 24 de dezembro de 2013, o processo havia sido apreciado pela Superintendência Geral, que em seu parecer, manifestou preocupações em relação a participação das duas instituições no mercado. Segundo o órgão, o fato de ambas empresas ofertarem cursos de graduação presencial e a distância (EAD) poderia causar potenciais impactos a livre concorrência.

Após a apreciação pela Superintendência Geral, coube ao Tribunal do Conselho Administrativo do órgão apreciar a matéria e sugerir acordos para extinguir os problemas apontados pela Superintendência. Em março de 2014, a Procuradoria Federal Especializada em conjunto com o $C A D E$, emitiu um parecer sugerindo a transferência de manutenção de instituições de ensino que operavam unicamente na modalidade EAD.

Os Srs. Bravo andavam bastante preocupados com os encaminhamentos do processo no CADE... Paulo tentava acalmá-los em mais uma, das inúmeras reuniões matinais de 
urgência, desde que o processo havia sido encaminhado para apreciação do órgão. A suspeitas dos Srs. Bravo de que o CADE trabalhava para prejudicar qualquer processo desse tipo, tinham sido confirmadas agora. Além dos impasses processuais, Alberto e Solange Bravo tiveram que aprender a lidar com o nome de sua organização "estampada" nas capas dos jornais e websites todos os dias.

O último parecer emitido pelo CADE havia gerado uma série de matérias publicadas na mídia, como a do jornal "O Estado de São Paulo", intitulada "Fusão de Gigantes da educação enfrenta impasse", que apontou haver indícios de informações que estavam sendo ocultadas pelas instituições participantes acerca do processo de incorporação. Na tentativa de "acalmar os ânimos" dos investidores, a Kroton e a Anhanguera se defenderam via emissão de comunicado ao mercado, afirmando que o conteúdo divulgado pelas matérias jornalísticas, incluindo a do Estado de São Paulo, não se sustentavam, visto que todas as informações concernentes ao processo de incorporação já haviam sido disponibilizadas em caráter tempestivo para todos os investidores.

-Não importa, Paulo! O que não pode acontecer é perder todo o valor investido até o momento e trair a confiança de nossos investidores! Retrucou Solange Bravo.

-Ok, Sra! Então esse rearranjo nos percentuais deverá acontecer! Defendeu-se Paulo.

-Eu já te disse que os rearranjos não importam! Eu só quero que esse processo seja concluído! Finaliza Solange Bravo, a caminho do hospital, devido uma "queda" de pressão pela sétima vez consecutiva naquela semana.

No dia 07 de maio de 2014, o acordo de associação entre as empresas passara por modificações quanto a proporção de capital entre os acionistas da Kroton e da Anhanguera, vigorando os valores respectivos de $66,5 \%$ e $33,5 \%$. Nesse aditivo, a Kroton esteve autorizada a distribuir $100 \%$ do lucro líquido no fim do exercício de 2014 , limitado ao total de $R \$ 483$ milhões.

Em 14 de maio de 2014, o CADE aprovou, em definitivo, a incorporação das ações da Anhanguera por parte da Kroton, mediante a celebração de um contrato de Acordo em Controle de Concentração. O CADE, fundamentado pelo disposto na Lei no 12.529/2002, avaliando os princípios da livre concorrência, da defesa dos consumidores e da repressão ao abuso do poder econômico; decidiu pela aprovação do processo, exigindo algumas contraprestações das empresas.

Dentre as contraprestações, destacaram-se: Alienação da Sociedade Educacional Leonardo da Vinci, atuante no mercado como Uniasselvi no estado de Santa Catarina, com unidades em Rondonópolis e Minas Gerais; Limitação do número de matrículas na modalidade EAD em 48 municípios; Proibição do uso concomitante das duas marcas em cidades onde ambas estivessem presentes; e investimento contínuo na capacitação de professores e tutores.

Ao fim do processo, a administração de ambas as companhias estimou o valor dos custos de incorporação em aproximadamente $\mathrm{R} \$ 35$ milhões, incluindo as despesas com publicações, custos da auditoria, honorários dos avaliadores, advogados e demais profissionais contratados para assessorar a operação.

Apesar do sentimento de insatisfação, os Srs. Bravo estavam felizes. Na visão deles, apesar do do processo não ter saído $100 \%$ conforme o esperado, "pelo menos" não houve a perda total do investimento realizado. Paulo também não estava satisfeito. As intempéries trazidas pelo CADE e pela mídia Ihe "furtaram" o sentimento de "dever cumprido". 
Na reunião de encerramento para apresentação dos custos globais da incorporação que acontecia naquela manhã, Paulo deixou claro estar disponível para "fazer tudo de novo", caso a Kroton tivesse interesse em realizar a incorporação de uma outra instituição.

Os Srs. Bravo se entreolharam... Paulo não perdia por esperar...

\section{DE VOLTA PARA KROTON, SEM MESMO SAIR DELA: UMA NOVA INCORPORAÇÃO.}

O sentimento de insatisfação permanecia entre os Srs. Bravo. Eles não haviam descansado desde o último processo de incorporação. Na visão deles, o "desgaste" daquele último processo deveria ser recuperado de alguma maneira. Deveria haver alguma forma daquele sentimento ser "sanado"... e foi nesse momento, que a provocação de Paulo na última reunião veio à tona...

Após a incorporação da Anhanguera, a Kroton passou a estudar a possibilidade de uma nova combinação de negócios, desta vez, com a Estácio Participações S.A., que desempenhava suas atividades de maneira concentrada no estado do Rio de Janeiro e nas regiões Norte e Nordeste.

A intenção da Kroton em propor essa incorporação, foi expandir a ocupação geográfica da empresa e obter maiores ganhos, a partir de uma maior sinergia econômica, bem maior do que aquela prevista na incorporação com a Anhanguera.

-Dessa vez será diferente! Aquele último processo me serviu para abrir os olhos... todo cuidado é pouco com o CADE e com a mídia, essa última pode interferir diretamente no sucesso de nossa nova incorporação... pensou, Paulo.

Diferente do primeiro processo, a Kroton emitiu um comunicado oficial ao mercado apenas com suas intenções com relação a Estácio. A instituição interessada ressaltou que, até aquele momento, não existia qualquer negociação em curso ou qualquer acordo com a empresa alvo.

De fato, Paulo e os Srs. Bravo levaram a sério a necessidade de se conduzirem com prudência, para que nenhuma informação fosse interpretada de maneia enviesada pela mídia. Eles foram além e decidiram "reforçar a guarda" nesse novo processo de incorporação.

A Kroton contratou o Banco Itaú BBA como assessor financeiro para o novo processo e o escritório Barbosa Müssnich Aragão, como assessor jurídico. Outra novidade foi que a potencial combinação não envolveria pagamento em dinheiro, mas ocorreria por meio da emissão de ações por parte da Kroton em favor dos acionistas da Estácio. Além de se resguardar da mídia, os Srs. Bravo evitariam movimentar valores altos em espécie, para evitar "chamar a atenção" do CADE em algumas operações desse novo processo.

O capital do novo projeto seguiria a proporção de $84,3 \%$ para os acionistas da Kroton, permanecendo com a intenção de representar a maior parte do capital; e de 15,7\% para os acionistas da Estácio. A empresa resultante da incorporação se tornaria uma das maiores do Brasil, com valor de mercado de mais de $\mathrm{R} \$ 26$ bilhões, alcançando uma receita líquida anual de R\$8 bilhões.

Paulo formalizou a proposta de associação entre as empresas por meio de correspondência enviada ao Conselho de Administração da Estácio. Após avaliação de consultoria realizada por ele, a Kroton concluiu que a melhor opção de associação entre as empresas seria por meio da incorporação de um outro percentual do capital da Estácio, que também seria cedido em forma de ações.

Decorrente da constatação de Paulo em sua consultoria, os Srs. Bravo decidiram alterar o valor e a proporção da participação dos acionistas da Estácio no capital. Na nova proposta, 
o valor definido foi de $\mathrm{R} \$ 1,28$ por ação, em que a entidade resultante da incorporação concentraria $80,8 \%$ das ações em posse dos acionistas da Kroton, em detrimento a $19,2 \%$ em posse dos da Estácio.

A proposta enviada pela Kroton foi aceita pelo Conselho de Administração da Estácio, que apesar da aceitação prévia, estava sujeita a trâmites legais e processuais. Os custos estimados pela companhia para realizar as operações iniciais como honorários decorrentes dos serviços de consultoria para avaliar a proposta foram $\mathrm{R} \$ 30$ milhões para cada uma das instituições, incluindo despesas com publicações, custos da auditoria e honorários com advogados e outras profissionais responsáveis por outras avaliações técnicas.

Ambas as empresas passaram a buscar as devidas aprovações de suas negociações. Em 08 de julho de 2016, os conselhos de administração de ambas aprovaram, por unanimidade, a incorporação de ações, junto a seu Protocolo e Jurisdição. Em 15 de agosto de 2016, as empresas conseguiram a aprovação de seus processos por suas Assembleias Gerais e em 31 de agosto de 2016, era chegado o grande dia: o processo foi submetido à apreciação do CADE.

Antes mesmo do parecer do $\mathrm{CADE}$, a mídia já se movimentava especulando cenários a respeito do andamento desse novo processo. O portal Reuters no Brasil publicou a notícia intitulada "Kroton avalia venda da área de ensino a distância da Estácio para ter o aval do CADE para a compra da empresa, dizem fontes". Nessa matéria, o portal Reuters apontava uma série de estratégias previstas por ambas as organizações para contornar "possíveis problemas" concorrenciais.

O portal Reuters insistiu na narrativa de que a Kroton avaliou a proposta de se desvincular da atividade de educação a distância da Estácio, para obter o aval antitruste no processo. A Kroton rebateu a matéria, via comunicado ao mercado, informando que o processo ainda estava em fase de instrução pelo CADE e que ela ainda não havia sido informada de eventuais medidas condicionantes a esta operação.

No dia 06 de fevereiro de 2017, a Superintendência Geral do CADE concluiu a apreciação do processo de incorporação, manifestando "preocupações concorrenciais", que motivaram - Tribunal do CADE a dilatar o prazo de tramitação do processo por duas vezes, por entender que havia certa complexidade, quanto ao impacto da concorrência para as demais organizações educacionais, neste processo de incorporação.

Não diferente dos prenúncios já sinalizados, no CADE, Fabio Pacioli, responsável por apreciar o processo de incorporação entre a Kroton e a Estácio decidiu não a aprovar, de maneira definitiva. A justificativa para isso? Se tratava de uma complexa operação dada a extensão das empresas envolvidas, que oferecia riscos, com alto impacto para a asseguração da livre concorrência para as demais organizações que atuam no mesmo setor.

Paulo estava atônito. Mais, uma vez, em sua cabeça não havia espaço para pensar em outra coisa a não ser: "O que fiz de errado?" "O que aconteceu dessa vez?".

$\mathrm{Na}$ mesma sala, os Srs. Bravo se entreolhavam na reunião matinal de urgência, convocada por eles para discutir sobre como os custos do processo perdido seriam absorvidos pela organização. Além disso, como enfrentar a mídia a partir daquele momento?

Alberto e Solange Bravo sabiam que em alguns dias, Fernando Costa, chefe do setor de incorporações, fusões e aquisições do Itaú e Barbosa Aragão, diretor chefe do escritório de advocacia, estariam em "sua porta" cobrando as garantias acertadas em contrato, independente do sucesso do projeto. Além disso, havia os consultores...para eles não importava o que aconteceu ao final, o serviço já havia sido prestado. 
Como Paulo deveria lidar com essa perda, visto que o retorno esperado pela incorporação com a Anhanguera ainda não havia sido alcançado? A única informação que ele dispunha era a de que esse retorno só seria visualizado em 36 meses após aquela incorporação...

Paulo não parava de se indagar: - "O que fiz de errado?” - “O que aconteceu dessa vez?”

\section{NOTAS DE ENSINO}

\subsection{FONTES DOS DADOS}

Para que o caso para ensino fosse elaborado, foi efetuado um registro cronológico, entre os anos de 2013 a 2017, de 15 comunicados ao mercado, 21 formulários de referência e 42 notas técnicas. Esta extensão de anos se deu por ser este o momento em que houve a divulgação inicial dos acordos de celebração, até o momento da aprovação e da não aprovação dessas incorporações pelo CADE.

Os comunicados ao mercado e os fatos relevantes divulgados pelas três organizações na Brasil Bolsa Balcão (B3) foram coletados e apresentados em uma planilha "lado a lado", para que fosse possível obter a perspectiva de mercado e a perspectiva organizacional desses eventos, a partir das informações fornecidas ao mercado, aos órgãos reguladores e aos de governança e aos investidores.

Com o objetivo de efetuar uma triangulação entre essas informações, as notícias divulgadas por portais de notícia (Exame, Infomoney, Reuters, O Estadão, Folha de São Paulo, G1, R7, Valor Econômico e da página eletrônica do próprio CADE) foram coletadas para que fosse possível acompanhar o comportamento da mídia em relação aos eventos e as divulgações de mercado.

Os personagens e os diálogos foram construídos com base nos eventos descritos em ordem cronológica, assim como, a relação com a Teoria Institucional, que se deu mediante comparação por data, entre o conteúdo apresentado nos comunicados ao mercado, fatos relevantes e as notícias, associadas por meio de suas epígrafes e do conteúdo das reportagens.

\subsection{OBJETIVOS EDUCACIONAIS}

O objetivo desse caso é auxiliar a compreensão de estudantes de graduação ou pósgraduação em como o profissional atua em situações que envolvem rearranjos organizacionais, mas especificamente, um processo de incorporação entre empresas.

A proposta foi elaborada com o intuito de que os estudantes pudessem compreender como as incorporações acontecem na prática, de maneira que possam enxergar a aplicação da teoria na prática. Esse caso para ensino busca fornecer uma visão analítica da atuação de um profissional no processo de incorporação, por meio das lentes institucionais (MOTTA; VASCONCELOS, 2009).

\subsection{ALTERNATIVAS PARA A ANÁLISE DO CASO}

Para análise do caso, a abordagem da Teoria Institucional (MEYER; ROWAN, 1977) serve para interpretar a atuação profissional de Paulo, considerando diversos elementos do ambiente corporativo da Kroton, que podem ter influenciado o processo de incorporação da Anhanguera por ela, ao mesmo tempo em que pode explicar o porquê do (in)sucesso na incorporação da Estácio. 
Alguns dos motivos apresentados pela literatura e que podem justificar a ocorrência de uma incorporação entre empresas, são: o ganho do poder de mercado, desenvolver sinergia operacional e financeira, economia no pagamento de impostos, gerenciamento de metas ineficientes e os custos de agência (CAPRON; PISTRE, 2002).

As teorias que surgiram das instituições, e que analisam o impacto da distância cultural, as diferenças regulatórias e as contingências institucionais nos eventos de reestruturação corporativa, são cada vez mais numerosas hoje em dia (BORTOLUZZO et al., 2014), isso se deu porque análises mais tradicionais centradas apenas nos aspectos econômicos e de mercado se revelaram insuficientes para apreender toda a complexidade inerente a um processo de incorporação.

Diferenças institucionais formais e informais, incluindo a atuação profissional e a maneira como as organizações são conduzidas, explicam as variações em um acordo anunciado de aquisição ao mercado e como essas diferenças influenciam a duração do processo de incorporação (DIKOVA; SAHIB; WITTELOOSTUIJN, 2010).

Há muitos anos, a teoria institucional tem servido de base para o estudo das organizações, principalmente quando se buscar explicar determinados fenômenos não abordados pela teoria clássica (MOTKE; RAVANELLO; ROFRIGUES, 2016). Segundo Vailatti, Silva e Vicente (2017) a Teoria Institucional compreende um conjunto de constructos teóricos oriundos de diversas áreas do conhecimento que fundamentam suas três correntes fundamentais: a Velha Economia Institucional (VEI), a Nova Economia Institucional (NEI) e a Nova Sociologia Institucional (NSI).

A Velha Economia Institucional está preocupada com as instituições que moldam as ações e pensamentos de agentes humanos individuais, considera a racionalidade limitada e o oportunismo das pessoas (SCAPENS, 2006). Segundo essa corrente de pensamento as pessoas vivem em ambientes institucionalizados, onde os hábitos e as rotinas pessoais tornam-se essenciais. Essa é a abordagem que mais se aproxima do impacto da atuação profissional sobre os rearranjos organizacionais.

A Nova Economia Institucional tem como foco as estruturas utilizadas para explicar as transações econômicas (SCAPENS, 2006), que juntamente com a abordagem sociológica, a NEI interpreta as organizações a partir de um olhar externo, examinando as pressões exercidas sobre suas práticas.

Um dos pontos abordados por essa vertente teórica se refere a legitimação de procedimentos perante as outras empresas. Essa abordagem defende que as organizações são induzidas a institucionalizar práticas proveniente da influência do ambiente externo (LUZ et al., 2018). Por sua vez, a Nova Sociologia Institucional se preocupa com as estruturas e sistemas organizacionais que dão forma ao ambiente corporativo das empresas (SCAPENS, 2006).

Este caso está fundamentado na abordagem da velha economia institucional, visto que a influência do institucionalismo nas incorporações podem ser analisadas sob a lente da atuação profissional nos rearranjos organizacionais, incluindo as incorporações. Estudos na área de estratégia e finanças mostraram que as incorporações podem beneficiar os acionistas, como parte interessada das empresas adquirentes, após criarem sinergia entre elas (CAPRON; PISTRE, 2002).

A sinergia organizacional foi a justificativa apresentada ao mercado pelos Srs. Bravo, donos da Kroton, para propor a incorporação da Anhanguera e da Estácio. Eles esperavam que 
essa sinergia acontecesse após combinação dos ativos e das competências para agregar qualidade aos serviços educacionais, inclusive por meio da recompra de ações.

Uma alternativa para análise do caso, consiste nos procedimentos adotados por Paulo para conduzir o processo de incorporação. Esses procedimentos poderiam ter influenciado o sucesso das incorporações. No caso elaborado, podemos constatar que a falta de um planejamento adequado e de conexão entre os projetos de investimento e a estratégia, assim como a comunicação defasada entre a alta administração e a diretoria, ou as falhas do processo decisório ou dos demais processos corporativos, podem ter influenciado os sistemas cognitivo e normativo das organizações, inclusive o grau de adesão entre as organizações e suas práticas (MOTTA; VASCONCELOS, 2009).

Em dado ambiente institucional, o aprendizado organizacional modera os efeitos da distância entre dois ambientes institucionais diferentes, este pode ser um motivo pelo qual o processo de incorporação entre a Anhanguera e a Kroton possa ter dado certo. A experiência com outros acordos de aquisição aumenta a probabilidade de que incorporações em ambientes institucionalmente mais próximos sejam mais duradouros, diferente de empresas com ambientes institucionais mais distantes (DIKOVA; SAHIB; WITTELOOSTUIJN, 2010).

Outra alternativa para análise do caso se dá pelo fato da Kroton apresentar um ambiente institucional com características mais próximas da Anhanguera. Isso pode ter favorecido a execução das imposições efetuadas pelo CADE, no momento que foi exigida a alienação da Uniasselvi e das duas unidades educacionais de Rondonópolis e Cuiabá. Diferente do que ocorreu no processo de incorporação entre Estácio e Kroton, quando o CADE impôs a redução de atividades na modalidade EAD, para que a parcela de participação no mercado de ensino a distância pudesse ser controlada e a concorrência das demais organizações não fosse prejudicada.

A utilização desse caso para ensino é recomendada para cursos de graduação e pósgraduação em Ciências Contábeis, Administração e Economia, por ter sido construído como uma proposta multidisciplinar, ao relacionar os temas atuação profissional, ambiente corporativo e operações de incorporação.

Recomenda-se o uso do caso para disciplinas como: Fundamentos Empresariais, Contabilidade Gerencial, Controladoria e Fundamentos de Análise de Investimentos; Planejamento Estratégico e Controle Financeiro, Governança Corporativa e Controladoria Avançada.

Para elaboração do plano de ensino, o professor responsável pela aplicação deve levar em consideração os quatro eixos que estruturam qualquer plano: objetivos, conteúdo, metodologia e avaliação. Como objetivo, a caso para ensino visa auxiliar a compreensão de estudantes de graduação e pós-graduação na relação entre a atuação profissional e um processo de incorporação. Além de auxiliar a compreensão, o caso visa desenvolver a capacidade dos estudantes identificarem como a teoria acontece na prática, no ambiente de uma prestadora de serviços educacionais.

Como alternativa para execução do caso, recomenda-se trabalhá-lo em sala durante duas aulas: A primeira, para apresentação do caso e de sua estrutura, seguido de uma leitura prévia, para explicitar os desdobramentos dos acontecimentos e a relação deles com a teoria. A segunda aula seria reservada para "coletar" as respostas dos alunos, estimulando a reflexão por parte deles e a interação por meio de debates.

Estes debates podem ser realizados por meio da divisão da turma em pequenos grupos, com as questões individualmente distribuídas entre eles, em forma de rodízio. Após 
discutirem em pequenos grupos, o professor é responsável por consolidar as ideias apresentadas durante a aula e encerrar o caso apontando uma solução que considere o máximo de opiniões apresentadas, de maneira convergente.

Durante a primeira aula, o professor deverá estar atento as dúvidas no decorrer da apresentação do caso. Para conduzir os debates na segunda aula, é importante o professor perceber que os alunos podem apontar elementos transversais (a importância de uma melhor remuneração para Paulo) como mais influentes no sucesso ou (in)sucesso das incorporações. Esta alternativa de resposta às questões reflexivas não pode ser considerado um erro.

Recomenda-se ao professor também estar atento para perceber a maneira como os alunos interpretam a existência e o funcionamento dos elementos corporativos. Caso os alunos apresentem uma visão mais normativa, eles poderão acreditar que a primeira incorporação só obteve êxito, mediante o cumprimento de exigências efetuadas pelo CADE à incorporadora; ou pelo fato de na segunda proposta de incorporação, a Kroton e a Estácio possivelmente não terem atendido exigências do CADE.

Para fins de avaliação e como alternativa de resposta ao dilema de Paulo, evidenciado no final do caso, os alunos podem ser incentivados a considerar outros fatores institucionais, como a projeção de receitas e o fluxo de caixa, a "pressão" exercida por outras instituições no mercado ou a influência da mídia nas etapas desses processos. O professor também deve estar atento para perceber que, a partir das indagações de Paulo, os alunos podem recomendar a reestruturação do "projeto perdido", visando diversificar o fluxo de receita da Kroton, propondo a esta investir em outras organizações menos complexas ou somente em parte da Estácio.

\subsection{QUESTÕES PARA A DISCUSSÃO DO CASO EM SALA DE AULA}

As questões para a discussão do caso problema (ROESCH, 2007) podem ser estruturadas entre questões reflexivas e interativas. As questões reflexivas servem para estimular a percepção crítica dos alunos sobre a relação entre a teoria e os eventos macro ambientais. Por possuírem o objetivo de estimular a reflexão, estas questões não apresentam uma única resposta como correta.

As questões interativas também não apresentam uma única resposta como correta, pois além de estimular a reflexão, também devem estimular o diálogo e o debate entre os alunos. Essas questões devem contribuir para aprimorar a capacidade crítico-argumentativa diante da abordagem trazida pelo caso.

As questões reflexivas podem ser trabalhadas conforme apresentado a seguir:

- Quais os elementos corporativos podem ser identificados no ambiente institucional da Kroton?

- Quais dentre os elementos corporativos apontados na questão anterior, podem ter influenciado de maneira direta, o sucesso e o (in)sucesso das incorporações?

- Como você avalia a atuação profissional de Paulo em ambos os casos? Quais as implicações de sua atuação profissional para o sucesso e (in)sucesso das incorporações?

- Como você avalia a relação interpessoal entre os Srs. Bravo e Paulo? Quais as implicações dessa relação para o sucesso e o (in)sucesso das incorporações?

Quanto as questões interativas, estas podem ser trabalhadas da seguinte maneira:

- Caso você estivesse no lugar de Paulo, como agiria em relação as responsabilidades destinadas pela Kroton para a primeira incorporação? E para a segunda? 
- Na sua concepção, quais os principais erros cometidos por Paulo a frente de seu cargo? E quanto a condução das incorporações?

- Quais sugestões de melhoria seriam dadas por você aos Srs. Bravo, quanto a estruturação dos projetos de incorporação? E para Paulo, quanto a condução desses projetos?

\subsection{BIBLIOGRAFIA RECOMENDADA PARA FUNDAMENTAR A ANÁLISE DO CASO}

Como sugestões de bibliografia, recomenda-se o uso de artigos científicos de periódicos reconhecidos pela CAPES e livros, voltados para os cursos de Ciências Contábeis, Administração e Economia, que estejam alinhados às disciplinas já mencionadas na seção 3.3 Alternativas para a análise do caso.

\section{REFERÊNCIAS}

BORTOLUZZO, A. B.; GARCIA, M. P. D. S.; BOEHE, D. M.; SHENG, H. H. Performance in crossborder mergers and acquisitions: an empirical analysis of the Brazilian case. Revista de Administração de Empresas, v. 54, n. 6, p. 659-671, nov./dez., 2014. DOI: http://dx.doi.org/10.1590/S0034-759020140606

BRASIL, BOLSA, BALCÃO. Fatos relevantes. Disponível em: http://www.bmfBovespa.com.br/pt_br/index.htm. Acesso em julho de 2017.

BRASIL. Estrutura o Sistema Brasileiro de Defesa da Concorrência; dispõe sobre a prevenção e repressão às infrações contra a ordem econômica, altera a Lei no 8.137, de 27 de dezembro de 1990, o Decreto-Lei no 3.689, de 3 de outubro de 1941 - Código de Processo Penal, e a Lei no 7.347, de 24 de julho de 1985; revoga dispositivos da Lei no8.884, de 11 de junho de 1994, e a Lei no9.781, de 19 de janeiro de 1999; e dá outras providências. Diário Oficial da República Federativa do Brasil, Poder Executivo, Brasília, DF, 30 nov. 2011. Disponível em: http:// www.planalto.gov.br/ ccivil_03 /_ato20112014/2011/Lei/L12529.html. Acesso em: 30 jun. 2017

BRASIL. Lei no 6404, de 1976. Dispõe sobre as Sociedades por Ações. Diário Oficial da República Federativa do Brasil, Poder Executivo, Brasília, DF, 15 dez. 1976. Disponível em: http://www.planalto.gov.br/ccivil_03 /leis /L6404 com pilada.htm. Acesso em: 1 jul. 2017.

COMISSÃO DE VALORES MOBILIÁRIOS (CVM). Instrução Normativa no 358, de 03 de janeiro de 2002. Revoga a Instrução CVM no 31, de 8 de fevereiro de 1984, a Instrução CVM no 69, de 8 de setembro de 1987, o art. 3 o da Instrução CVM no 229, de 16 de janeiro de 1995, o parágrafo único do art. 13 da Instrução CVM 202, de 6 de dezembro de 1993, e os arts. 30 a 11 da Instrução CVM no 299, de 9 de fevereiro de 1999, e dá outras providências. Rio de Janeiro, RJ, 03 jan. 2002. Disponível em: http://www.cvm.gov.br/legislacao/instrucoes/inst358.html. Acesso em: 04 jul. 2017.

CONSELHO ADMINISTRATIVO DE DEFESA ECONÔMICA (CADE). Regimento Interno. 2017. Disponível em: http://www.cade.gov.br/noticias/cade-publica-novo-regimento-interno. Acesso em: 1 jun. 2017. 
DIKOVA, D.; SAHIB, P. R.; WITTELOOSTUIJN, A. V. Cross-border acquisition abandonment and completion: The effect of institutional differences and organizational learning in the international business service industry. Journal of International Business Studies, v. 41, n. 2, p. 223-245, fev., 2010. DOI: https://doi.org/10.1057/jibs.2009.10

GREENWOOD, R.; OLIVER, C.; LAWRENCE, T. B.; MEYER, R. Introduction: Into the Fourth Decade. The SAGE Handbook of Organizational Institutionalism. 2.ed. Londres: Sage, 2017, p. 1-23.

KROTON EDUCACIONAL. Sobre a Kroton - Perfil Corporativo. Disponível em: http://www.kroton.com.br/. Acesso em julho de 2017.

LUZ, I. P.; LISBOA, F.V.; LAVARDA, C. E. F.; VICENTE, E. F. R. Teoria Institucional: uma análise bibliométrica na pesquisa em Contabilidade. Revista de Educação e Pesquisa em Contabilidade (REPeC), v. 12, n. 4, out./dez., 2018. DOI: https://doi.org/10.17524 /repec.v12i4.1873

MEYER, J. W.; ROWAN, B. Institutionalized organizations: Formal structure as myth and ceremony. American Journal of Sociology, v. 83, n. 2, p. 340-363, set.,1977. DOI: https://doi.org/ 10.1086/226550

MOTTA, F.; VASCONCELOS, I. Teoria Geral da Administração. 3. ed. São Paulo: Cengagelearning, 2009.

MOTKE, F. D.; RAVANELLO, F. S.; RODRIGUES, G. O. Teoria institucional: um estudo bibliométrico da última década na Web of Science. Revista Contemporânea de Economia e Gestão - Contextus, v. 14, n. 2, p. 63-86, mai./ago., 2016. DOI: https://doi.org/10.19094 /contextus. v14i2.792

ROESCH, S. M. A. Notas sobre a construção de casos para ensino. Revista de Administração Contemporânea, v. 11, n. 2, p. 213-234, abr./jun., 2007. DOI: http://dx.doi.org/10.1590 /S1415-65552007000200012

SCAPENS, R. W. Understanding management accounting practices: A personal journey. The British Accounting Review, v. 38, n.1, p. 1-30, mar., 2006. DOI: https://doi.org/10.1016/j.bar. 2005.10. 002

VAILATTI, J. L.; ROSA, F. S.; VICENTE, E. F. R. A Teoria Institucional aplicada à Contabilidade Gerencial: análise da contribuição teórica e metodológica de publicações internacionais ocorridas no período de 2006 a 2015. Revista Catarinense da Ciência Contábil, v. 16, n. 47, jan./abr., 2017. DOI: https://doi.org/10.16930/2237-7662/rccc.v16n47p97-111

WEBER, S. A.V. Transformação, incorporação, fusão e cisão. Business Review: Revista de Negócios da Unifin., v. 11, p. 2013, set., 2008. 